Alex Tiong-Heng Sia MB BS MMED

\title{
Optimal dose of intrathecal clonidine added to sufentanil plus bupivacaine for labour analgesia
}

Purpose: The combination of intrathecal (IT) $5 \mu \mathrm{g}$ sufentanil plus $1.25 \mathrm{mg}$ bupivacaine is useful for inducing labour analgesia, albeit of short duration and slow onset. As a supplementation to this regimen, the effect of IT clonidine on the duration of analgesic action was investigated.

Methods: Forty-eight healthy parturients were randomly assigned into three groups to receive $0 \mu \mathrm{g}$ (group C0), $15 \mu \mathrm{g}(\mathrm{Cl}$ ) $)$ or $30 \mu \mathrm{g}$ (C30) of clonidine IT in addition to $5 \mu \mathrm{g}$ sufentanil plus I. $25 \mathrm{mg}$ bupivacaine IT for labour analgesia. The quality of pain relief was assessed on $0-100$ visual analogue scale by the author. The occurrence of side effects was also evaluated before the request for additional analgesia.

Results: Clonidine ( $\mathrm{Cl} 5$ and $\mathrm{C} 30$ ), produced a longer duration of analgesia than $\mathrm{CO}$ (mean I $44 \pm$ sd 27.9, 165 $\pm 31.8 \mathrm{vs} / \mathrm{II} \pm 21.9 \mathrm{~min}, P<0.0 \mathrm{I}$ ). Also, $\mathrm{Cl} 5$ and $\mathrm{C} 30$ produced a more rapid onset and a higher quality of analgesia than $\mathrm{CO},(P<0.0 \mathrm{I})$. The most cephalad level of sensory block was higher in $\mathrm{C} 30$ than $\mathrm{Cl} 5$ (median T3 vs T4, $P<0.05$ ) but lowest in C0 (median T7 vs T3,T4, $P<0.01$ ). Side effects, sedation and hypotension, occurred more frequently in $\mathrm{C} 30$ than in either $\mathrm{C} 0$ or $\mathrm{Cl}$ 5, ( 9 vs 2,5 and 9 vs I,3, respectively, $P<0.05$ ).

Conclusion: The optimal dose of intrathecal clonidine to enhance labour analgesia with the current sufentanilbupivacaine regimen is $15 \mu \mathrm{g}$. In view of the side effect profile, doses greater than $30 \mu \mathrm{g}$ clonidine are unlikely to be useful.

Objectif : La combinaison de l'administration intrathécale (IT) de $5 \mu \mathrm{g}$ de sufentanil et de 1,25 mg de bupivacaiine est utile pour induire l'analgésie du travail obstétrical, quoique de courte durée et d'un lent délai d'installation. Comme apport complémentaire à ce régime, de la clonidine IT a été administrée et son effet sur la durée de l'action analgésique a été mesuré.

Méthode : L'étude a porté sur 48 parturientes en bonne santé, réparties de façon aléatoire en trois groupes et qui ont reçu $0 \mu \mathrm{g}$ (groupe C0), ou I $5 \mu \mathrm{g}$ (CI5) ou $30 \mu \mathrm{g}$ (C30) de clonidine IT en plus de $5 \mu \mathrm{g}$ de sufentanil et de I,25 mg de bupivacaiine IT comme analgésie pendant le travail. La qualité de l'analgésie a été évaluée par l'auteur sur une échelle visuelle analogique de 0-100. L'occurrence d'effets secondaires a aussi été notée avant la demande d'analgésie additionnelle.

Résultats : Les doses de clonidine $\mathrm{Cl} 5$ et $\mathrm{C} 30$ ont produit une analgésie plus longue que la C0 (moyenne I44 \pm écart type 27,$9 ; 165 \pm 31,8$ vs $1111 \pm 21,9 \mathrm{~min} ; P<0,01$ ). De plus, $\mathrm{Cl} 5$ et $\mathrm{C} 30$ ont provoqué un début d'action plus rapide et une meilleure qualité d'analgésie que $C 0,(P<0,0 \mathrm{I})$. Le bloc sensitif le plus haut, en direction céphalique, a été obtenu avec $C 30$ comparé à $\mathrm{Cl} 5$ (médiane $T_{3}$ vs $T_{4}, P<0,05$ ) et a été plus bas avec $C 0$ (médiane $T_{7} v s T_{3}, T_{4}, P<0,0 \mathrm{I}$ ). Les effets secondaires, la sédation et l'hypotension, sont survenus plus souvent avec C30 qu'avec C0 ou Cl 5, (9 vs 2,5 et 9 vs I,3 respectivement, $P<0,05$ ).

Conclusion : La dose optimale de clonidine intrathécale, nécessaire pour améliorer l'analgésie pendant le travail, combinée au régime habituel de sufentanil-bupivacaïne est de $15 \mu \mathrm{g}$. En regard des effets secondaires, des doses de clonidine plus élevées que $30 \mu \mathrm{g}$ ne sont pas vraiment utiles.

From the Department of Anaesthesia, KK Women's and Children's Hospital, 100 Bukit Timah Road, Singapore 229 899, Singapore. Address correspondence to: Dr. A.T.H. Sia. Fax: 65-291-2661; E-mail: athsia@kkh.com.sg

Accepted for publication May 14, 2000. 
$\mathrm{T}$ HE administration of intrathecal (IT) sufentanil plus bupivacaine is a popular method of inducing labour analgesia. This is usually employed as the initial part of a combined spinal epidural (CSE) technique. Previous studies showed that the combination of IT $10 \mu \mathrm{g}$ sufentanil plus $2.5 \mathrm{mg}$ bupivacaine provided effective analgesia for early labour. ${ }^{1,2}$ In an earlier study, we found that halving the dose of IT $10 \mu \mathrm{g}$ sufentanil plus $2.5 \mathrm{mg}$ bupivacaine reduced the incidence of side effects, such as hypotension, sedation and motor blockade. ${ }^{3}$ However, this reduced dose regimen was associated with a slower onset and shorter duration of action.

Intrathecal clonidine, either alone or in combination with other agents, improves analgesia in labour. ${ }^{4-6}$ There are no reports on the dose-response relationship of the addition of IT clonidine on labour analgesia rendered by spinal sufentanil-bupivacaine combination. This study was designed to determine the optimal dose of IT clonidine (in terms of hastening the onset and prolonging the duration of analgesia) that could be added to the combination of IT 5 $\mu \mathrm{g}$ sufentanil plus $1.25 \mathrm{mg}$ bupivacaine.

\section{Methods}

In a randomized, double-blinded, controlled study conducted with the approval of the hospital research ethics committee, 48 ASA physical status I nulliparous parturients in established labour (of at least one painful contraction in five minutes) who were scheduled to receive CSE were studied.

The exclusion criteria were cervical dilatation $>5$ $\mathrm{cm}$, weight $>90 \mathrm{~kg}$, age $>40 \mathrm{yr}$, administration of meperidine $i m<$ four hours before CSE and the presence of obstetric complications (such as preeclampsia, multiple pregnancy, preterm labour and noncephalic presentation).

A pre-block pain score (on a 0-100 visual analog scale, $0=$ no pain and $100=$ worst pain imaginable), systolic blood pressure (measured non-invasively on the left arm) and an external fetal heart tracing were obtained in each parturient. Each parturient received a pre-load of 0.5 L lactated Ringer's iv solution for hydration.

After obtaining written, informed consent for the study, the parturients were randomized (by sealed envelope assignment) to receive $0 \mu \mathrm{g}$ (group $\mathrm{C} 0$, $n=16$ ), $15 \mu \mathrm{g}$ (group $\mathrm{Cl} 5, n=16$ ) or $30 \mu \mathrm{g}$ (group C30, $n=16$ ) of clonidine (Boebringer Ingelheim) IT in addition to $5 \mu \mathrm{g}$ sufentanil (Janssen) plus plain 1.25 mg bupivacaine (Astra Zeneca) IT. Combined spinal epidural analgesia was instituted in the left lateral position at the $\mathrm{L}_{2-3}$ or $\mathrm{L}_{3-4}$ level by using the 'needle through needle' technique (Becton Dickinson Durasafe set). In this technique, the epidural space was accessed with a 17 gauge Weiss needle by using the loss of resistance to air method, followed by dural puncture with a 27 gauge Whitacre spinal needle.

Every parturient received the same volume of $4 \mathrm{~mL}$ of the IT test solution (diluted in isotonic sodium chloride) and was unaware of its contents. The test solution was prepared by one of the author's assistants not involved in the assessment of the parturient after CSE was instituted by the author, who was blinded to the drugs used. In every case, the IT solution was injected over $20 \mathrm{sec}$. The epidural catheter was inserted $3 \mathrm{~cm}$ into the epidural space. No epidural test dose was given. Unsuccessful dural taps after three attempts excluded the parturients from the study and epidural analgesia was instituted accordingly. In the first minute after CSE, all the parturients were turned to the supine position with a wedge to effect left uterine displacement. The evaluation of the parturients was done by the author.

For the first half hour after CSE, automated maternal systolic blood pressure (Dinamap) was charted at five minute intervals. Pain scores, maximal degree of lower limb motor block (based on a modified Bromage scale i.e.: $0=$ no motor block, $\mathrm{l}=$ able to move knee and ankle, $2=$ able to move ankle, $3=$ complete block) and the highest sensory block to cold (ice) were assessed 5, 15 and $30 \mathrm{~min}$ after CSE. In each case, the study ended when the request for additional analgesia was made by the parturient. The duration of analgesia was taken as the time from CSE to the request for additional analgesia. During this period, the parturients were observed every $15 \mathrm{~min}$ for the first $30 \mathrm{~min}$ and every $30 \mathrm{~min}$ thereafter for shivering and the maximal degree of sedation $($ none $=$ awake and alert, mild $=$ awake but drowsy, moderate $=$ asleep but rousable, severe $=$ not rousable). The presence of nausea ( \pm vomiting) and pruritus was also noted. The parturients were also observed for the evidence of respiratory depression, i.e. respiratory rate of $<8$ breaths per min and/or shallow breathing at five minute intervals.

The duration of analgesia, systolic blood pressure and the parturients' height and weight were analyzed by one-way analysis of variance (ANOVA) and, if indicated, post hoc Tukey test for pair-wise comparisons. Motor block, sedation scores and the highest degree of sensory block were analyzed by using Kruskal Wallis and post hoc Dunn's tests if necessary. The quality of analgesia during the first 30 min was assessed by analysis of the area under the curve attributed to pain scores. Serial pain scores were analyzed by ANOVA for 


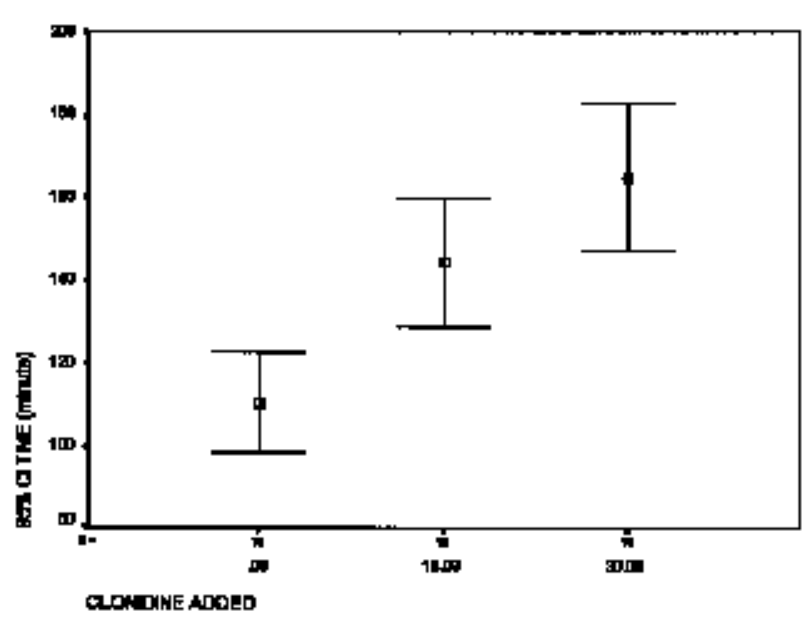

FIGURE 1 Duration of analgesia.

The mean and $95 \%$ confidence interval value of $\mathrm{C} 0, \mathrm{Cl} 5$ and $\mathrm{C} 30$ are shown.

Significant difference $(\mathrm{p}<0.01)$ was found between $\mathrm{C} 0$ and the other two groups. No significant difference was found between C15 and C30.

(Analysis by ANOVA and post hoc Tukey test for pair-wise comparison)

repeated measures. Dichotomous data were analyzed using $\chi^{2}$ and Fisher exact test with the application of Bonferroni's inequality as appropriate. With $\alpha=0.05$ and $\beta=0.2$, the sample size was computed to detect an additional $30 \mathrm{~min}$ of analgesia for the study groups (i.e. $\mathrm{C} 15$ and $\mathrm{C} 30)$ in comparison with the control group (C0). A $P$ value of $<0.05$ was considered statistically significant.

Results

One parturient from group C0 was precluded from analysis because, after CSE, more than five minutes was taken to reinsert the epidural catheter after an initial bloody aspirate. Two parturients ( 1 in C15, 1 in C30) were excluded from analysis because delivery occurred before they complained of pain after CSE. Therefore, 15 parturients in each group were analyzed.

There were no differences detected in the demographic data, cervical dilatation and the use of oxytocin before CSE. (Table I)

The duration of analgesia (the primary study outcome) was shorter in C0 than in the groups that had received clonidine $(P<0.01)$ but there was no difference between C15 and C30. (Figure 1)

Although baseline pain scores were similar among the groups, they were higher in C0 at 5 min after CSE $(P<0.01)$. This suggested that the onset of analgesia

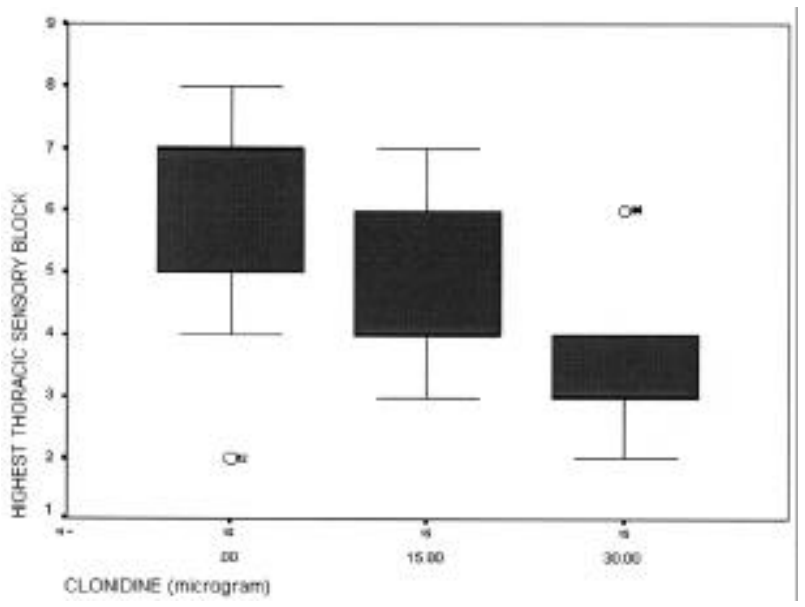

FIGURE 2 Highest thoracic dermatomal block

The median, inter-quartile range and the maximum values of the highest thoracic block are shown.

Significant difference was found comparing $\mathrm{C} 0$ with $\mathrm{C} 15$ and C $30, \mathrm{p}<0.01$

Significant difference was found between C15 with C30, $\mathrm{p}<0.05$

(Analysis by Krustal Wallis and post hoc Dunn's test for pair-wise comparison)

had been reduced by the addition of clonidine. The quality of analgesia was also improved by the addition of clonidine because, at $15 \mathrm{~min}$ and $30 \mathrm{~min}$ after CSE, pain scores were higher in the group that did not receive clonidine $(P<0.01)$. The faster onset and higher quality of analgesia was also confirmed by the analysis of the area under the curve described by the pain scores over the $30 \mathrm{~min}$ duration of assessment. There was no difference in the quality of analgesia between $\mathrm{C} 15$ and C30. (Table II)

The highest dermatome block to cold was lower in $\mathrm{C} 0$ than in the other two groups, $P<0.01$. The highest dermatome block was also lower in $\mathrm{Cl} 5$ in comparison with C30, suggesting a dose effect relationship of clonidine with regard to the cephalad spread of sensory block, $P<0.05$. (Figure 2)

There were no differences in the baseline pre-block and the lowest post-block systolic blood pressure among the three groups. We compared the incidence of 'hypotension' and the lowest blood pressure achieved (instead of serial blood pressures among the groups) as it was more practical and arguably more clinically relevant. In our study, a decrease of $>20 \%$ of the pre-block systolic blood pressure (categorically termed 'hypotension') was immediately treated with additional $i v$ fluids and $6 \mathrm{mg}$ boluses of ephedrine every minute; which could have explained the lack of 
TABLE I Demographic data

\begin{tabular}{|c|c|c|c|}
\hline & $\begin{array}{l}C 0 \\
n=15\end{array}$ & $\begin{array}{l}\text { C15 } \\
n=15\end{array}$ & $\begin{array}{l}\text { C30 } \\
n=15\end{array}$ \\
\hline Weight (kg) & $63.9 \pm 9.9$ & $68.2 \pm 9.8$ & $70.6 \pm 9.5$ \\
\hline Height $(\mathrm{cm})$ & $157 \pm 4.9$ & $154 \pm 5.6$ & $159 \pm 7.0$ \\
\hline \multicolumn{4}{|l|}{ Baseline systolic blood } \\
\hline pressure $(\mathrm{mm} \mathrm{Hg})$ & $117.8 \pm 9.9$ & $115.3 \pm 11$ & $114.9 \pm 10$ \\
\hline Cervical dilatation $(\mathrm{cm})$ & $4(2-5)$ & $3(2-5)$ & $3(2-5)$ \\
\hline Preblock oxytocin use & 8 & 7 & 8 \\
\hline \multicolumn{4}{|c|}{ Level of CSE introduction } \\
\hline $\mathrm{L}_{2-3}$ & 2 & 1 & 3 \\
\hline $\mathrm{L}_{3-4}^{2-3}$ & 13 & 14 & 12 \\
\hline
\end{tabular}

All values represent mean \pm sd except median (range) for cervical dilatation and $n$ for preblock oxytocin used and level of CSE. No were differences found among the groups.

TABLE II Pain scores (0-100mm Visual analogue scale)

\begin{tabular}{|c|c|c|c|}
\hline & $\begin{array}{l}C 0 \\
n=15\end{array}$ & $\begin{array}{l}C 15 \\
n=15\end{array}$ & $\begin{array}{l}\text { C30 } \\
n=15\end{array}$ \\
\hline Pain score at $0 \mathrm{~min}$ & $89(65-100)$ & $90(60-100)$ & $85(55-100)$ \\
\hline Pain score at $5 \mathrm{~min}$ & $9(0-43)^{*}$ & $0(0-25)$ & $0(0-15)$ \\
\hline Pain score at $15 \mathrm{~min}$ & $2(0-15)^{*}$ & $0(0-10)$ & $0(0-12)$ \\
\hline Pain score at $30 \mathrm{~min}$ & $0(0-15)^{*}$ & $0(0-10)$ & $0(0-10)$ \\
\hline \multicolumn{4}{|c|}{ Area under the curve (AUC) } \\
\hline of pain scores & $360 \pm 115^{*}$ & $249 \pm 45.2$ & $220 \pm 94.1$ \\
\hline
\end{tabular}

All values are expressed as median (maximum - minimum) except AUC as mean \pm sd

${ }^{*} P<0.01$ between $\mathrm{C} 0$ and the other two groups. No difference found between $\mathrm{C} 15$ and C30.

TABLE III Lowest systolic blood pressure and side effects

\begin{tabular}{llll}
\hline & $\begin{array}{l}\text { C0 } \\
n=15\end{array}$ & $\begin{array}{l}\text { C15 } \\
n=15\end{array}$ & $\begin{array}{l}\text { C30 } \\
n=15\end{array}$ \\
\hline $\begin{array}{l}\text { Lowest systolic blood } \\
\text { pressure (mmHg) }\end{array}$ & $92.1 \pm 17.8$ & $97.3 \pm 9.1$ & $91.0 \pm 11$ \\
$\begin{array}{l}\text { Hypotension } \\
\text { Sedation: mild }\end{array} \quad 1(7)$ & $3(20)$ & $9^{*}(60)$ \\
$\quad$ moderate & 2 & 4 & 4 \\
$\quad$ severe & 0 & 1 & 5 \\
$\quad$ total & $2(14)$ & $5(33)$ & 0 \\
Shivering & $3(20)$ & $2(14)$ & $4(27)$ \\
Nausea & $0(0)$ & $1(7)$ & $1(7)$ \\
Pruritus & $5(33)$ & $3(20)$ & $7(47)$ \\
\hline
\end{tabular}

All values are expressed as $n$ (percentage) except the lowest systolic blood pressure as mean \pm sd.

* $P<0.05$ between C30 and the other groups.

difference in the lowest post-block blood pressure among the groups. However, in comparison with the other groups, a higher proportion of parturients in C30 had categorical hypotension $(P<0.05)$. Indeed, all the hypotensive episodes were readily treated.
There was also a higher incidence of sedation in C30 than in $\mathrm{C} 0$ and $\mathrm{C} 15, P<0.01$. There were no differences in the incidence of the other side effects. None of the parturients had any detectable lower limb motor block. (Table III)

The continuous fetal heart tracing within the first hour of CSE was monitored by an obstetrician. Two parturients in group C15,2 in C30 and 1 in C0 had transient fetal heart rate changes within $60 \mathrm{~min}$ of CSE $(P>0.05)$; none of the parturients required an emergency abdominal delivery.

\section{Discussion}

The addition of $15 \mu \mathrm{g}$ or $30 \mu \mathrm{g}$ of clonidine IT hastened the onset, prolonged the duration and improved the quality of labour analgesia produced by $5 \mu \mathrm{g}$ sufentanil plus $1.25 \mathrm{mg}$ bupivacaine IT . However, in comparison with $15 \mu \mathrm{g}$, the addition of $30 \mu \mathrm{g}$ of clonidine IT was associated with a higher incidence of hypotension and sedation. In spite of that, there were no clinically evident adverse effects. Nevertheless, in the current study, the higher dose of clonidine did not offer any further advantage in terms of a shorter time of onset or a longer duration of analgesia. Therefore, although both doses of IT clonidine may be used in conjunction with the current sufentanil-bupivacaine regimen, the outcome of our study suggests that $15 \mu \mathrm{g}$ clonidine IT probably approaches the optimal dose. It is doubtful that such a low dose of clonidine IT would have any negative repercussion on the neonate. A previous study that had used a dose as high as $30 \mu \mathrm{g}$ clonidine IT for the induction of labour analgesia did not detect the drug in the fetal circulation at delivery. ${ }^{4}$

Low to moderate doses of neuraxially administered clonidine produce hypotension via $\alpha_{2}$ agonism; by the inhibition of preganglionic sympathetic activity in the spinal cord and the reduction of sympathetic drive in the brainstem. ${ }^{6}$ A previous study found that the use of $30 \mu \mathrm{g}$ clonidine combined with $5 \mu \mathrm{g}$ sufentanil IT resulted in a higher incidence of hypotension than $5 \mu \mathrm{g}$ sufentanil IT for labour analgesia. ${ }^{5}$ In view of the potential interaction between bupivacaine and clonidine in further enhancing the extent of sympatholysis (hence, exacerbating the degree of hypotension), we did not use a dose higher than $30 \mu \mathrm{g}$ clonidine. Moreover, in a direct comparison with another study, Gautier inferred that a dose of $30 \mu \mathrm{g}$ clonidine was as effective as 100 or $200 \mu \mathrm{g}$ in potentiating analgesia from sufentanil IT for labour pain relief. In that study, $30 \mu \mathrm{g}$ clonidine IT as the sole agent was found to provide effective analgesia for $80 \%$ of the parturients. ${ }^{4}$ Despite the observation that the increased incidence of hypotension was not 
clinically significant, the addition of a dose much higher than $30 \mu \mathrm{g}$ clonidine IT to the currently already efficacious regimen of sufentanil plus bupivacaine IT is probably superfluous and may be inadvisable.

Sedation is a known effect of clonidine due to its $\alpha_{2}$ agonistic action on the locus coeruleus in the brainstem. The incidence of sedation after CSE could be decreased by reducing the dose of intrathecal sufentanil. ${ }^{3}$ Our results show a dose dependent increase in the incidence of sedation from the addition of clonidine IT. Although sedation may be a desired effect in many perioperative situations, the clinical advantage of this effect on labouring women is debatable at best. A recent study found that sedation was one of the main reasons why parturients chose to remain recumbent even though they were clinically devoid of lower limb motor and posterior column block after CSE in labour. ${ }^{2}$

The observation of a higher incidence of sedation rendered by the combination of clonidine and sufentanil could be disturbing to the anesthesiologist. This is because increasing somnolence (possibly caused by hypercarbia) could be construed as the herald to severe respiratory depression after the administration of neuraxial opioids. ${ }^{7}$ A lower dose of sufentanil IT, such as the $5 \mu \mathrm{g}$ dose employed in this study, may be safer because, in the obstetric population, respiratory arrest, despite being an exceedingly rare occurrence, could be related to doses of $10 \mu \mathrm{g}$ of sufentanil or higher IT, based on evidence from case reports. ${ }^{8,9}$ In our study, the increased incidence of sedation did not seem to be related to any adverse respiratory effect although we did not use pulse oximetry and our sample size was small. Recent findings suggested that clonidine (either alone or in association with opioids), does not cause or potentiate respiratory depression to an appreciable extent. ${ }^{11}$ Similarly, the higher sensory block produced by the addition of clonidine (due possibly to the its interaction with bupivacaine and sufentanil in enhancing nerve conduction blockade) was not associated with any clinical evidence of motor block and did not contribute to any respiratory problems. The incidence of sedation related to clonidine IT was lower in our parturients than in a recent study which had also investigated the effect of sufentanilbupivacaine-clonidine combination IT. ${ }^{10}$ This could have been partly due to the higher dosages of sufentanil and clonidine, $7.5 \mu \mathrm{g}$ and $50 \mu \mathrm{g}$, respectively, used in that study.

The ability to prolong the analgesic effect of the intrathecal component of the CSE modality offers the practical advantage of diminishing the need for subsequent "top-up" analgesia. While the outcome of our current study shows that clonidine prolonged the dura- tion of analgesia, its impact is questionable as more than $90 \%$ of the parturients had required a subsequent topup before delivery ensued. Therefore, to this end, more research is required. Although the addition of neostigmine IT could enhance the clonidine-induced analgesia contributed by the cholinergic pathway, a recent study showed that this fell short of producing optimal analgesia because of an unacceptably high incidence of emesis. ${ }^{11,12}$ In addition, an earlier study showed that the addition of clonidine improved the quality and duration of epidural analgesia produced by bupivacaine-epinephrine-sufentanil combination during labour even though the integrated effect of intrathecal clonidine plus epinephrine on the commonly used intrathecal bupivacaine-sufentanil regimen for labour analgesia has thus far remained largely undetermined. ${ }^{13}$

In conclusion, our study shows that the addition of $15 \mu \mathrm{g}$ or $30 \mu \mathrm{g}$ of clonidine IT to $5 \mu \mathrm{g}$ sufentanil plus $1.25 \mathrm{mg}$ bupivacaine IT hastened the onset and prolonged the duration of analgesia for early labour. Side effects, hypotension and sedation, were more common with the larger dose. In view of this side effect profile, the additional value of a dose greater than 30 $\mu \mathrm{g}$ of clonidine IT with respect to the current sufentanil-bupivacaine regimen is doubtful.

\section{References}

1 Campbell DC, Camann WR, Datta S. The addition of bupivacaine to intrathecal sufentanil for labor analgesia. Anesth Analg 1995; 81: 305-9.

2 Sia ATH, Chong JL, Tay DHB, Lo WK, Chen LH, Chin $J W$. Intrathecal sufentanil as the sole agent in combined spinal-epidural analgesia for the ambulatory parturient. Can J Anaesth 1998; 45: 620-5.

3 Sia ATH, Chong JL, Chin JW. Combination of intrathecal sufentanil $10 \mu \mathrm{g}$ plus bupivacaine $2.5 \mathrm{mg}$ for labor analgesia: is half the dose enough? Anesth Analg 1999; 88: 362-6.

4 Gautier PE, De Kock M, Fanard L, Van Steenberge A, Hody J-L. Intrathecal clonidine combined with sufentanil for labor analgesia. Anesthesiology 1998; 88: 651-6.

5 Mercier FJ, Dounas M, Bouaziz H, et al. The effect of adding a minidose of clonidine to intrathecal sufentanil for labor analgesia. Anesthesiology 1998; 89: 594-601.

6 Chiari A, Lorber C, Eisenach JC, et al. Analgesic and hemodynamic effects of intrathecal clonidine as the sole analgesic agent during first stage of labor. Anesthesiology 1999; 91: 388-96.

7 Chaney MA. Side effects of intrathecal and epidural opioids. Can J Anaesth 1995; 42: 891-903.

8 Hays RL, Palmer CM. Respiratory depression after intrathecal sufentanil during labor. Anesthesiology 1994; 81: 511-2. 
9 Jaffee JB, Drease GE, Kelly T, Newman LM. Severe respiratory depression in the obstetric patient after intrathecal meperidine or sufentanil. Int J Obst Anesth 1997; 6: 182-4.

10 D'Angelo R, Evans E, Dean LA, Gaver R, Eisenach JC. Spinal clonidine prolongs labor analgesia from spinal sufentanil and bupivacaine. Anesth Analg 1999; 88: 573-6.

11 Eisenach JC, De Kock M, Klimscha W. Alpha 2 -adrenergic agonists for regional analgesia. A clinical review of clonidine (1984-1995). Anesthesiology 1996; 85: 655-74.

12 D'Angelo, Dean L, Meister G, Nelson K. Labor analgesia from spinal neostigmine, sufentanil, bupivacaine and clonidine. Anesthesiology 1999; 91: Al 057.

13 Claes B, Soetens M, Van Zundert A, Datta S. Clonidine added to bupivacaine-epinephrine-sufentanil improves epidural analgesia during childbirth. Reg Anesth Pain Med 1998; 23: 540-7. 